\title{
Servicio Público y \\ Derecho Comunitario Europeo ${ }^{1}$
}

\author{
Jaime Rodríguez - Arana*
}

\begin{abstract}
Hoy en dia la realidad nos plantea una nueva visión del Derecho Administrativo, que en su búsqueda del interés general se vislumbra como "Derecho Administrativo Constitucional" y ello es también, una proyección del Estado social democrático y de Derecho. Entonces, el autor nos plantea la evolución del derecho administrativo desde el Estado social hasta el Estado garantizador en que el servicio público resulta un elemento clave para la configuración del concepto.

Asimismo, el autor define nuevos conceptos señalados por la Comisión Europea que muy acertadamente remarcan el relativismo e instrumentalidad del Derecho Administrativo, que complementan elementos del régimen del servicio público (continuidad y regularidad) y del mundo moderno (no monopolio). Enfatizando, no la preeminencia del mercado, sino la definición del Estado en relación con los servicios públicos: Derecho público para garantizar el bienestar de todos.
\end{abstract}

\section{Introducción}

El servicio público, lo sabemos muy bien, es un tema clásico del Derecho Administrativo que sirvió como punto cardinal para explicar el significado mismo de nuestra disciplina. Para DUGUIT y su escuela de Burdeos, precisamente del "Servicio Público", éste constituyó el fundamento y limite de la soberanía, el centro neurálgico del Derecho Público.

La pretensión de buscar un criterio único, de validez universal y de carácter atemporal para fundamentar el Derecho Administrativo, pone de manifiesto la imposibilidad real de levantar todo el edificio del Derecho Administrativo bajo un solo y único concepto: el servicio público, elaborado, además, desde la atalaya del privilegio y de la prerrogativa. Más bien, esta tarea nos invita a situarnos en otros parámetros $y$, asimismo, nos interpela sobre la caracterización de nuestra área de conocimiento como temporal, relativa y profundamente integrada en el contexto constitucional de cada momento. Quizás, por eso, OTTO MAYER sentenciaría aquello tan manido y reiterado, "el Derecho Constitucional pasa, el Derecho Administrativo permanece".

La misma mutabilidad de las instituciones, categorías y conceptos del Derecho Administrativo en función del marco constitucional y del entendimiento que se tenga del interés general, demuestra el distinto alcance y funcionalidad que pueden tener las técnicas jurídicas del Derecho Administrativo en cada momento.

Quizás por ello, durante la década de los cincuenta del siglo pasado, se admitió la tesis de la "noción imposible" para señalar las obvias e insalvables dificultades para perfilar un concepto estático y unilateral del servicio público como paradigma del Derecho Administrativo. El advenimiento del Estado social colocó de nuevo al servicio público, ahora desde una perspectiva más amplia, en el lugar central. Es el tiempo de la expansión de las actividades estatales en la sociedad y aparecen, por ello, bajo la rectoría del Estado, los servicios de educación, sanidad, transportes, entre otros tantos.

Simplificando mucho las cosas, tarea que es la propia de una intervención oral de esta naturaleza, se puede afirmar que la constitución del concepto del servicio público siempre despertó una penetrante y aguda polémica con las libertades públicas y los derechos fundamentales. Es más, la tensión entre poder y libertad siempre corrió pareja al binomio, a veces en grave confrontación dialéctica, Estado - Sociedad. Y, es lo más probable, de esta dicotomía nacerían tanto la técnica autorizatoria como la institución concesional, fieles reflejos del diferente grado de intervención que se reservaba el Estado en relación con la vida social. Ciertamente, el nacimiento de la concesión

Catedrático de Derecho Administrativo de la Universidad de A Coruña Presidente del Foro lberoamericano de Derecho Administrativo. Agradecemos al autor por cedernos personalmente la publicación del presente artículo.

1 Texto de la intervención del autor en el Seminario Internacional de la Asociación de Derecho Público de MERCOSUR, el día 23 de abril de 2004 en Salta (Argentina). 
administrativa como modo indirecto de gestión de los servicios públicos se inscribe en el proceso de deslinde, desde el marco de la exclusividad, de titularidad y gestión de la actividad, toda vez que llegó un momento en pleno Estado liberal en que el Estado no se consideraba digno de mediar en el mundo de la economia, sector que debía gestionarse aguas arriba del propio Estado.

En fin, la crisis del Estado de Bienestar, por situarnos en fechas más próximas para nosotros, junto a las consabidas explicaciones fiscales, obedece también a la puesta en cuestión de un modelo de Estado, que, al decir de FORSTHOFF todo lo invade y todo lo controla "desde la cuna hasta la tumba". Ciertamente, al menos desde mi particular punto de vista, la otrora institución configuradora del orden social, como fue la subvención, debe replantearse, como todas las técnicas del fomento en su conjunto. Este modelo estático al Estado de Bienestar situó a los servicios públicos y al propio Estado como fin, no como medio para el bienestar de los ciudadanos. De ahi su agotamiento y, por ello, su crisis.

La confusión entre fines y medios ha tenido mucho quever con las aproximaciones unilaterales y tecnoestructurales del interés general que, en este enfoque se reduce a autocontrol y la conservación del "status quo".

Hoy, desde los postulados del Estado dinámico del Bienestar, veremos como el servicio público en sentido técnico - juridico apenas cuenta $y$, no se si en su lugar, pero la realidad manifiesta la emergencia de los servicios de interés general, o los servicios de interés económico general $y$, por ende, se produce una vuelta al Derecho Administrativo, por supuesto diferente al del siglo pasado, más desafiante si cabe en su papel esencial de construir técnicas jurídicas que garanticen el bienestar integral de los ciudadanos. O, lo que es lo mismo, se trata de construir un Derecho Público que haga posible el libre desarrollo de los ciudadanos y, por ello, el pleno ejercicio de los derechos fundamentales por todas las personas. Aparece asi, en mi opinión, el Estado garantizador y, con el, toda una serie de nuevos conceptos, categorías e instituciones que nacen de una nueva forma de aproximarse al Derecho Administrativo: el pensamiento abierto, plural, dinámico y complementario, que no es sino la dimensión jurídica de los nuevos enfoques reinantes hoy en las Ciencias Sociales.

El Estado, pues, ya no es un mero prestador de servicios públicos. El Estado es, sobre todo y ante todo, garantizador de derechos y libertades ciudadanas, para lo cual goza de un conjunto de nuevas técnicas juridicas que le permiten cumplir cabalmente esa función.

Por tanto, el concepto del servicio público, deudor de una concreta y peculiar manera ideológica de entender las relaciones Estado - Sociedad, pierde su sentido jurídico - administrativo al desvanecerse el marco general que le servía de apoyo. Se reduce notablemente en su configuración por cuánto ahora lo normal y ordinario es la realización de determinadas actividades de relevancia pública en régimen de libertad, en régimen de competencia. Por ello, insisto, en un nuevo marco, aparecen nuevos conceptos que ponen en cuestión la versión clásica de la noción del servicio público.

\section{Servicio Público y Derecho Administrativo Constitucional}

En España, esta aproximación, propia del tiempo en que vivimos, es consecuencia de la proyección del Estado social y democrático de Derecho sobre la funcionalidad de la Administración pública y encuentra soporte en lo que Jose Luis MEILAN GIL denomina desde hace bastante tiempo Derecho Administrativo Constitucional.

¿Cuáles serán, entonces, las bases constitucionales de este nuevo Derecho Administrativo? En mi opinión, la Constitución de 1978 nos ofrece presupuestos más que suficientes para edificar el moderno Derecho Administrativo.

El artículo 9.2 plantea lo que se ha denominado la función promocional de los Poderes Públicos en la medida en que su papel constitucional reside precisamente en promover la libertad e igualdad de los ciudadanos y de los grupos en que se integran y, sobre todo, en remover los obstáculos que se opongan a esta tarea. Aquí nos encontramos, con toda claridad, con la función constitucional por antonomasia de la Administración pública en el Estado social y democrático de Derecho en nuestro tiempo que es la de garantizar el ejercicio de todos los derechos por todos los ciudadanos, con especial referencia a los más necesitados.

En el articulo 10.1, la Constitución proclama que los derechos fundamentales y el libre desarrollo de la personalidad constituyen el fundamento del orden públicoydelapazsocial,estableciendomeridianamente hacia donde se orienta el interés general en el Estado social y democrático de Derecho.

El artículo 24.1 proclama la tutela judicial efectiva y prohíbe toda situación de indefensión, lo cual supone la necesidad de releer y repensar, desde la Constitución, muchos de los dogmas y principios que han levantado el edificio del Derecho Administrativo y que, hoy en día, deben ser claramente replanteados.

También encontramos un vector constitucional relevante en el artículo 31.2, cuando caracteriza el gasto público en un contexto de economía, planteando que la acción administrativa en el Estado social es limitada y debe producirse en un contexto de austeridad porque el presupuesto público no es de propiedad de la Administración, sino de los ciudadanos y, los funcionarios, no son ni más ni menos que agentes de intereses púbíicos. 
$\mathrm{Y}$, finalmente, el artículo 103.1, que es el precepto cabecera de la opción constitucional en esta materia. Vale la pena, siquiera sea brevemente, una muy breve glosa. Pues bien, el precepto en cuestión dice, en su párrafo primero:

"La Administración pública sirve con objetividad, los intereses generales (...) y actúa con sometimiento pleno a la ley y al Derecho".

En primer lugar, debe subrayarse de nuevo la naturaleza instrumental de la Administración pues la utilización del término "sirve" alimenta esta explicación $\sin$ mayores dificultades. En efecto, entre las muchas caracterizaciones posibles, el constituyente quiso dejar bien claro que la Administración pública es una persona jurídica - pública que se realiza en la medida en que está al servicio del interés general. Ciertamente, se pudo haber elegido algún otro término que también encajase en la Administración en relación con el interés general: representar, defender, gestionar..., pero la realidad es que se quiso deliberadamente configurar la Administración pública desde este punto de vista.

En segundo lugar, merece la pena llamar la atención sobre la manera en que la Administración debe llevar a efecto su esencial función de servicio al interés general. Esto es, el servicio habrá de ser objetivo. Es decir, la Administración pública es una organización imparcial y neutral que se limita, y no es poco, a la tarea de la ejecución de la ley. Por eso, en materia de contratación, se rige por el principio de publicidad y concurrencia, $y$, en materia de personal, de acuerdo con los criterios de mérito y capacidad. Se trata, pues, de criterios esenciales a los que debe someterse la Administración pública, sea en sus actuaciones directas o a través de fórmulas instrumentales, hoy tan de moda.

En tercer lugar, el precepto constitucional señala la finalidad pública del quehacer administrativo: "servicio objetivo al interés general", que, aplicado al Estado social y democrático de Derecho que define la Constitución española, nos sitúa en esa dimensión promocional y garantizadora anteriormente señalada.

En cuarto lugar, debe tenerse en cuenta que el articulo 103.1 de la Constitución de 1978 se refiere a la Administración pública en singular, por lo que debe entenderse que el sistema que diseña debe predicarse tanto de la Administración del Estado, como de la Administración autonómica, provincial o local.

Y, finalmente, el precepto alude a que la Administración pública actúa con "sometimiento pleno a la ley y al Derecho". Ordinariamente, será el Derecho Administrativo su matriz normativa de referencia pero, en ocasiones, el aparato público actuará sujeto al Derecho Privado. Ahora bien, en estos casos en que su Derecho regulador es el privado, en modo alguno significa, solo faltaría, que se quedaran al margen los criterios esenciales de la actuación administrativa. En otras palabras, la objetividad, que es una nota constitucional, exige que los principios y vectores jurídicos quele son consustanciales se apliquen siempre que estemos en presencia de fondos públicos.

La articulación del Derecho Administrativo Constitucional sobre el servicio público requiere analizar, siquiera brevemente, dos preceptos de la Constitución aparentemente contradictorios $y$, sin embargo, complementarios. Me refiero, claro está, al artículo 38 y al 128 .

\section{El artículo 38 dispone:}

"Se reconoce la libertad de empresa en el marco de la economía de mercado. Los poderes públicos garantizan y protegen su ejercicio y la defensa de la productividad, de acuerdo con las exigencias de la economía general $y$, en su caso, de la planificación"

Por su parte, el artículo 128 establece:

"1.- Toda la riqueza del país en sus distintas formas y, sea cual fuere su titularidad está subordinada al interés general"

2.- Se reconoce la iniciativa pública en la actividad económica. Mediante ley se podrá reservar al sector público recursos o servicios esenciales, especialmente en caso de monopolio y asimismo acordar la intervención de empresas cuando así lo exigiere el interés general".

Es decir, el principio es el de la libertad económica en el marco del Estado socialy democrático de Derecho, porlo que los Poderes públicos tienen la tarea garantizadora a la que antes he hecho referencia, que, en determinados casos puede aconsejar, por ley, la reserva al Estado en exclusiva de determinados servicios denominados esenciales. Evidentemente, está posibilidad debe ser motivada en la Ley que opere la reserva como exigencia del interés general. Pienso que, en cualquier caso, el régimen ordinario es el de libertad en el marco del Estado social, lo que supone, ciertamente, que el régimen clásico del servicio público con sus notas tradicionales: titularidad y exclusividad, ya no encaje en el marco constitucional como fórmula ordinaria de prestación de los servicios públicos. Aunque, repito, en determinados casos, se pueda reservar en exclusiva al sector público determinados servicios esenciales, cuando razones de interés general lo aconsejen.

Por tanto, aunque hoy siga teniendo vigencia los motivos de la "publicatio", en la versión de solidaridad social (DUGGIT) o procura existencial (FORSTHOFF), sin embargo, la expresión real de la prestación de los servicios ya no es la técnica de la "publicatio", salvo excepciones, sino la técnica autorizadora ("ordenatio") cuando no la simple certificación por la Administración de la idoneidad técnica del particular para prestar el servicio.

El principio es la libertad, pero modalizado o contextualizado por la dimensión solidaria que le es 
inherente. Entonces, la Administración pública, insisto, garantiza la libertad en la prestación de los servicios de interés general con arreglo precisamente a su propia funcionalidad. Las exigencias del principio de libertad solidaria en la prestación de los servicios de interés general, no se puede olvidar, se derivan de la libertad de elección de servicios que asiste a los ciudadanos, a los usuarios.

\section{“(...)la Administración pública, insisto, garantiza la libertad en la prestación de los servicios de interés general con arreglo precisamente a su propia funcionalidad."}

La referencia al usuario como centro de gravedad del régimen de los servicios de interés general y los postulados del pensamiento abierto, plural, dinámico y complementario, dibujan un nuevo mapa, una nueva hoja de ruta en la que situar el régimen actual de los denominados servicios de interés general.

No se puede olvidar que, en este ambiente, se ha planteado una de las principales tensiones que la teoría de los servicios de interés general parece solucionar. Me refiero a la tradicional polémica entre servicio público y derechos fundamentales - libertades públicas. Desde la teoría del servicio público, es claro que la titularidad pública choca frontalmente con el núcleo esencial de la libertad económica y que, por el contrario, la teoría del servicio de interés general permite el juego del binomio libertad - interés general desde la perspectiva garantizadora de la función del Estado.

Además, no podemos perder de vista algo muy importante y que para el Derecho Administrativo es esencial: la realidad. Hoy, guste o no, existe un gradual proceso de despublicación, de desregulación, o, si se quiere, de privatización que plantéa el gran desafío común de definir el papel del Estado en relación con los servicios públicos. En Europa, tras los Tratados fundacionales y Maastricht, es menester tener presente que la realidad del Mercado Único se llama libre competencia y que, por ello, la Administración pública no puede mirar para otro lado. Lo que no quiere decir, insisto, que la Administración pública ceda inerme ante los encantos del mercado. No, pero tampoco es de recibo alimentar versiones caducas que hablen de que el Estado sea la encarnación del ideal ético, como pretendía HEGEL.

\section{El Derecho Administrativo en la historia}

Algunos autores piensan que la pérdida de sentido hoy de la noción clásica del servicio público es poco menos que una traición al Derecho Administrativo. Quienes así piensan, con todos mis respetos (sólo faltaría) no son conscientes de que, precisamente a través de la emergencia de nuevos conceptos como el del servicio de interés general, o el servicio de interés económico general, el Derecho Administrativo, nuestra disciplina, está recobrando el pulso y un protagonismo inusitado, tal y como intentaré demostrar al exponer brevemente la situación del régimen juridico de las telecomunicaciones en Europa, y especialmente en mi país: España.

No se trata, pues, de certificar sólo, para el tiempo presente, la muerte de una categoría jurídico - administrativa que en su día jugó un papel muy destacado en la recuperación del viejo continente tras la Segunda Guerra Mundial; se trata de registrar el nacimiento de un nuevo Derecho Administrativo que, a través de nuevas instituciones, sigue buscando, como ansiaba IHERING, la mejor regulación de la gestión del interés general.

Hoy, por todo ello, reaparece con toda su fuerza el Derecho Administrativo, en la materia que nos ocupa, en forma de servicio de interés general o servicio económico de interés general: justamente la categoría que utiliza el Derecho Comunitario Europeo para definir esta especial posición jurídica del Estado en relación con los antaño denominados servicios públicos.

Como es sabido, en los denominados servicios económicos de interés general (luego examinaré el supuesto de las telecomunicaciones) la función de garante del Estado aparece en todo su vigor a través de las Ilamadas obligaciones de servicio público, entre las que el servicio universal es la más típica y caracteristica, y dónde mejor se contempla esa nueva función del Estado garante.

Sin embargo, frente a los nostálgicos del servicio público queson los mismos que nos han inundadode pesimismo enarbolando la bandera de la huída del Derecho Administrativo, me atrevo, con modestia, a afirmar que hoy asistimos a una vuelta al Derecho Administrativo, eso sí, desde los postulados del pensamiento abierto, plural, dinámico y complementario y a partir de la necesaria superación de apriorismos y prejuicios metodológicos del pasado.

Los que nos dedicamos al estudio del Derecho Administrativo hemos comentado tantas veces que nuestra disciplina se caracteriza por hundir sus raices en las movedizas arenas de la realidad, que sabemos, y somos testigos cualificados, de que los diferentes sentidos e interpretaciones que acompañan a los conceptos de nuestra disciplina son deudores precisamente del cambiante marco constitucional en el que discurren. Quizás, por ello, el proceso de 
liberalización y desregulación que hoy nos toca vivir es una oportunidad para seguir defendiendo el Derecho Administrativo como ese Derecho del poder para la libertad, de manera que la función de garantía de esa libertad, en el marco del Estado social, es su principal señal de identidad.

Para algunos, las consecuencias de la realidad que es, valga la redundancia, la que es, han traído consigo un me parece que injusto proceso al servicio público tal y como señala REGOURD. No es, sin embargo, un ajuste de cuentas metodológico o conceptual, Dios me libre, a la tradición del Derecho Administrativo francés; por cierto, de la que todos hemos aprendido tantas cosas. En su momento, como quería DUGUIT, sí que el servicio público era la piedra angular que justificaba la propia existencia del Estado. Luego, algunos, como ALESSI, señalaron que había tantas nociones del servicio público como autores se han acercado a su conceptualización. VEDEL llamó la atención sobre la elasticidad y flexibilidad de una noción que, para él, era perversa precisamente por su imposibilidad de definición. WALINE nos alertó sobre la condición de "etiqueta" del servicio público. En fin, que no negamos su trascendencia en el pasado, pero afirmamos que en el presente ya no tiene apenas razón de ser como no sea en los supuestos, en verdad excepcionales, de reservar al sector público en exclusiva servicios esenciales.

Antes de la crisis definitiva del concepto, se puede hablar de dos momentos difíciles para nuestra categoría. La primera crisis se puede datar en la segunda mitad del siglo XIX cuando al Estado no le queda más remedio que asumir las prestaciones asistenciales básicas como la sanidad y la educación. Y, además, se hace con la titularidad de los servicios económicos de mayor trascendencia, especialmente lo que hoy denominaríamos grandes inversiones públicas. Aparece entonces, con su proverbial magisterio a la cabeza de la Escuela de Toulouse, HAURIOU, quien nos dejaría, para mí, la mejor definición del servicio público: "servicio técnico prestado al público de manera regular y por una organización pública". Era el momento de aqueila fenomenal polémica sobre la esencia del Derecho Administrativo entre los grandes: JEZE, seguidor de DUGUIT, de los de Burdeos - el servicio público - y VEDEL, a la zaga de la Escuela de Toulouse - el poder público o las famosas cláusulas exorbitantes - .

En lo que se refiere a la actividad económica, el Estado asume la titularidad renunciando a la gestión en virtud de la conocida doctrina del concesionario interpuesto. Así, la declaración del servicio público implica desde el principio la titularidad pública, mientras que la gestión se confía a los particulares. Más adelante, el espacio local, que siempre es el mejor laboratorio del Derecho Administrativo, nos lleva, de la mano de los fabianos en el Reino Unido, a los supuestos de municipalización de servicios públicos municipales. En 1929, la gran depresión trae consigo la quiebra de los grandes concesionarios, por lo que será el Estado, y ya no digamos en Europa tras la II Gran Configuración, quien tenga que correr con la responsabilidad, también, de la prestación directa de los servicios.

La segunda crisis, en la que todavía estamos instalados de algún modo, viene de la mano del nuevo ídolo del altar de las ideas públicas, como señala el profesor Tomás-Ramón FERNÁNDEZ: la competencia. En efecto, la competencia, la liberalización es la palabra que utilizan las fuentes originarias y derivadas del Derecho Comunitario Europeo. Es, se dice, el dominio de la economía. Es, se dice, el apogeo de los economistas y de las Escuelas de Friburgo - la competencia es la clave del desarrollo económico (EUCKEN) - , de Viena - principio de no intervención pública (HAYEK), de Chicago - guerra a los monopolios (FRIEDMAN) - , o de "Public Choice" - la realidad en cada caso aconsejará si lo procedente es la iniciativa pública o privada (BUCHANAN) -.

Ciertamente, si alguien puede pararelfundamentalismo económicoenlavidasocial,esunDerechoAdministrativo para el que la clave, en materia de servicios públicos - en sentido amplio - es prestar servicios que mejoren las condiciones de vida de los ciudadanos. Este es el "punctum dolens" de nuestra reflexión: lo decisivo no es quien preste el servicio sino que éste promueva la libertad solidaria de los ciudadanos o, si se quiere, posibilite un mejor ejercicio de los derechos por parte de las personas. Es decir, que incida favorablemente en las condiciones de vida de las personas y promueva la elección de los servicios.

En este contexto se comprenderá la aseveración de Pierre DEVOLVÉ cuando afirma categóricamente que el servicio público es la principal amenaza para las libertades públicas. Por tanto, el nuevo concepto de servicio económico de interés general que se alumbra en el marco de Derecho Comunitario Europeo es la expresión del moderno Derecho Administrativo y el concepto desde el que contemplar la posición del Estado en la nueva economía.

Por un lado, el avance científico y tecnológico ha arrumbado esa versión estática de la "publicatio" que antaño justificaba la existencia del servicio público en la insuficiencia de capital privado para asumir los grandes servicios económicos y sociales. $Y$, por otro, no podemos negar guste o no, que la globalización económica ha traido consigo la existencia de grandes empresas con un potencial superior al de algunos Estados que, además, pueden, en ocasiones, gestionar mejor los servicios públicos tradicionales.

\section{Servicio Público y Derecho Administrativo Comunitario}

En este ambiente, el Derecho Comunitario Europeo asestaal servicio público, en sentido estricto, el principal golpe de gracia por mor de la libre competencia, que se convierte en el corazón de la integración económica que preside el Mercado Único Europeo. Privatización, desregulación, liberalización, "despublicatio", no son 
más que términos jurídicos (económicos o económico) que han certificado la defunción de la titularidad pública de tantos servicios.

Finalmente, quiero señalar que el jurista no debe, no puede permanecer insensible ante el intento de dominio del Derecho Público por la Economía. No, los que cultivamos el Derecho Administrativo tenemos que levantar la voz y clamar que el interés general no ha muerto a manos de la eficacia del mercado. Más bien, el mercado debe entenderse, desde el pensamiento abierto, plural, dinámico y complementario, en un marco de interés general que garantice el equilibrio entre poder y libertad.

Lógicamente, la incidencia de las nuevas nociones de la Política Económica han traído consigo esta segunda y definitiva crisis del servicio público y la aparición de nuevos conceptos, entre los que destacaría el de servicio económico de interés general, que, como sabemos, procede del Derecho Comunitario.

En efecto, resulta curioso, y hasta sorprendente, que en el Derecho Comunitario Europeo no aparezca la expresión servicio público como no sea en el artículo 73 de la versión consolidada del Derecho originario. ¿Por qué? Probablemente, por la disparidad de regímenes jurídicos utilizados en los Derechos Nacionales en orden a asegurar a los ciudadanos peticiones esenciales con carácter general, regular y continua. En síntesis, los países de la Unión Europea se dividen entre los que siguen, en este punto, servicio con "publicatio" y régimen exorbitante de cuño francés, y los que se alinean con las denominadas "public utilities" garantizadas por la regulación (sin más) de la actividad de los sujetos privados prestados de dichos servicios, de orientación claramente anglosajona.

Pues bien, para no optar por una u otra tradición jurídica, el Derecho Comunitario alumbra el metaconcepto de "servicio económico de interés general" o "el de servicio de interés general". Por eso, en el vigente artículo 86.2 del Tratado de la Unión Europea se puede leer que "las empresas encargadas de la gestión de servicios de interés económico general quedarán sometidas a las normas de este Tratado, en especial a las de la competencia" ${ }^{\prime 2}$.

Por tanto, el Derecho de la Unión Europea es un Derecho que ha traído consigo la liberalización que, a su vez, ha afectado a la organización institucional de los servicios públicos de los Estados miembros de la Unión.

Sin embargo, es conveniente llamar la atención sobre el sentido que tiene la aparición del calificativo "interés general". Así, la Comunicación de la Comisión sobre los servicios de interés general en Europa, de setiembre de 1996, vinculó de modo explícito los servicios de interés económico general a los principios de solidaridad e igualdad de trato como "objetivos fundamentales de la Comunidad".
En el mismo sentido, el Tratado de Ámsterdam introdujo en el texto dispositivo del Tratado de la Unión el nuevo artículo 16 de la versión consolidada que establece lo siguiente:

"... a la vista del lugar que los servicios de interés económico general ocupan entre los valores comunes de la Unión, así como de su papel en la promoción de la cohesión social y territorial, la Comunidad y los Estados miembros, con arreglo a sus competencias respectivas y en el ámbito de aplicación del presente Tratado, velarán por que dichos principios actúen con arreglo a principios y condiciones que les permitan cumplir su cometido".

La jurisprudencia del Tribunal de Justicia de la Comunidad Europea, que inicialmente combatió, quizás excesivamente, las potestades públicas en esta materia a partir de la interpretación del artículo 90.2 del Tratado en sede de ayudas públicas, ha pasado a una línea en la que lo decisivo es que cada vez se presten mejor los servicios públicos, en una orientación claramente relacionada con la función del Estado de garantizar el interés general. Por ejemplo, en la sentencia 320/91 de 19 de mayo de 1993 en materia de servicio postal, se reconoció que en dicho servicio de interés económico general habia que comprobar si la aplicación de las reglas de la libre competencia impediría el cumplimiento de las reglas de interés general. Así, el Tribunal entendió en este caso, que la realización del interés general llevaba consigo "la gestión de modo rentable del servicio y, por tanto, que la necesidad de compensar pérdidas del servicio público en sectores no rentables mediante los beneficios obtenidos de otros sectores económicamente rentables justificara que en estos últimos se limitara el juego de la competencia a favor de los particulares".

En la sentencia del 27 de abril de 1994, asunto 393/92, el Tribunal, en un caso de distribución de electricidad y de una cláusula de compra exclusiva en beneficio de una empresa regional de distribución eléctrica de Holanda, recordó la necesidad de valorar el criterio del equilibrio económico, no sólo entre sectores rentables y no rentables, sino que deben tenerse presente las obligaciones de interés general, como las reglamentaciones que debe soportar en materia de medio ambiente, de ordenación del territorio o de seguridad entre otras.

Pues bien, la principal obligación de interés general en estos supuestos es la del servicio universal, que asegura la prestación en todo caso y la calidad alli dónde el mercado no funciona bien, por falta de rentabilidad o como consecuencia de una mal entendida competencia. Como analizaremos a continuación, estas obligaciones nacen en el marco del Derecho Europeo de las Telecomunicaciones. Así, en los servicios de interés económico general hay que distinguir prestaciones susceptibles de ser realizadas en régimen de mercado y prestaciones no susceptibles de prestaciones 
competitivas. En este caso, la Autoridad impone la prestación obligatoria a algún operador para la que se arbitre algún sistema de compensación económica.

Por ejemplo, en atención a que los servicios de telecomunicación cumplen una función muy relevante en la sociedad de la información, la Comisión Europea dictó una Comunicación en 1999 al Consejo, al Parlamento, al Comité Económico y Social y al Comité de las Regiones sobre "el servicio universal de las telecomunicaciones ante la perspectiva de un entorno plenamente liberalizado".

Pero ya que hemos entrado en un servicio económico de interés general concreto, me voy a permitir aplicar a este sector, la doctrina que con carácter general hemos planteado hasta el momento.

La reciente Ley española 32/2003, de 3 de noviembre (BOE número 264 de 4 de noviembre de 2003), lleva como rúbrica "General de Telecomunicaciones" y sustituye a la Ley $11 / 1998$, de 24 de abril, del mismo nombre. Como es sabido, trae causa de la necesidad de incorporaral Derecho Español un conjunto de Directivas comunitarias que se han elaborado recientemente con el objeto de consolidar, como dice la Exposición de Motivos de la Ley de 2003, el marco armonizado de libre competencia en las telecomunicaciones alcanzado en los Estados miembros.

En esencia, las Directivas Comunitarias dictadas en 2002 se refieren al marco regulador de las comunicaciones electrónicas yalas redes ylos servicios decomunicaciones electrónicas. Especialmente interesante es la 2002/22 CE del Parlamento Europeo y del Consejo, de 7 de marzo de 2002, relativa al servicio universal y los derechos de los usuarios en relación con las redes y los servicios de comunicaciones electrónicas. Cuestión, la del servicio universal, que ha supuesto, nada más y nada menos, una fuerte sacudida a los intentos, a veces vacilantes $y$, en todo caso dubitativos, que ha producido la desregulación de un sector tradicionalmente sujeto a monopolio. El desconcierto es tal que los enterradores del concepto clásico del servicio público han empezado a sospechar que la vuelta de este concepto tiene mucho que ver con el llamado servicio universal $y_{1}$ sobre todo, con las denominadas obligaciones de servicio público. Sin embargo, la realidad es que ahora el Estado interviene en la vida económica desde enfoques abiertos, no unilaterales. El servicio público, pues, queda para los supuestos, que pueden darse en circunstancias especiales, de reserva, exclusividad y titularidad de la actividad de que se trate.

Las instituciones, conceptos y categorias de Derecho Administrativo, lo sabemos bien, están en una relación estrecha, estrechísima, con la realidad que les ha tocado en suerte. Es más, soy de los que pienso que no debemos escandalizarnos, ni metodológica ni cientificamente, por el hecho de que las principales manifestaciones del Derecho Administrativo se presenten de forma diversa según las circunstancias sociales, políticas y económicas de tiempo y de lugar. En efecto, es lógico que así sea porque tras los diversos avatares por los que ha pasado esta disciplina es lo cierto que somos testigos cualificados de la mudanza de sus instituciones, sin que, por ello, haya desaparecido el Derecho Administrativo.

Pues bien, en esta tarea me parece que es conveniente recordar que el Derecho Administrativo puede definirse como el Derecho del Poder para la libertad o, si se quiere, el Derecho que regula los intereses generales que sirve con objetividadla Administración Pública. En este sentido, todas las categorías, instituciones y conceptos centrales del Derecho Administrativo deben orientarse al interés general. Es decir, deben estar abiertos a hacer posible y visible ese metaconcepto del interés general que, en un Estado social y democrático de Derecho, está vinculado a la tarea promocional y garante de los Poderes públicos orientada al libre y efectivo ejercicio de los derechos fundamentales por parte de los ciudadanos. Asi la sanidad, la educación o la vivienda, deben gestionarse de manera que la ciudadanía pueda disponer de un acceso general a estos bienes. Lo público deber estar abierto a la ciudadanía y las necesidades públicas deben manejarse de manera que, efectivamente, la Administración pública tienda al bienestar general de todos.

En nuestro país, la simple lectura, por ejemplo, de los artículos 9.2, 10.1, 31.2, o 103.1 de nuestra Constitución, como he expuesto anteriormente, nos invita a estudiar el Derecho Administrativo en el marco constitucional y, por ello, a tener muy presente los parámetros y vectores constitucionales. De ahí que, hoy por hoy, en un modelo de Estado social y democrático de Derecho en el que los derechos fundamentales de la persona ocupan un lugar central, el ejercicio de los poderes y funciones públicas debe operarse teniendo presente la libertad yla igualdad de los individuos y de los grupos en que se integran, es un objetivo constitucional; que los fundamentos del orden político y la paz social residen en el libre desarrollo de las personas y en los derechos que les son inherentes; que el gasto público debe gestionarse con criterios de economía, o que la Administración Pública sirve con objetividad los intereses generales. En definitiva, la Administración pública, al gestionar lo público, no se puede olvidar del bienestar de todos, eso sí, haciendo del bienestar un concepto dinámico, no estático, al servicio de las personas.

En este contexto, resulta en mi opinión imprescindible, también para el estudio del Derecho Administrativo, situarse en los postulados del pensamiento abierto, plural, dinámico y compatible. Porque el interés general debe interpretarse fuera del pensamiento único: Tanto del que intenta aislar al interés general en el santuario del tecnosistema, como del que intenta a toda costa desmantelar lo público para entregarlo"in toto" al sector privado. Sobre todo, porque, insisto, lo público, en un Estado social y democrático de Derecho, debe definirse de manera abierta entre el Poder y los agentes sociales ya que se terminó una forma de entender la Administración y ei poder de naturaleza autoritaria y vertical. 
Llegados a este punto, en sede de servicio público, la contemplación de la realidad nos puede dejar algo confusos o perplejos, sobre todo si intentamos aplicar los criterios y categorías del pasado. ¿Es que se puede mantener la noción clásica de servicio público hoy? La contestación a ésta pregunta no es difícil. Lo que pasa en ocasiones es que las exigencias del mercado, o de las liberalizaciones, desregulaciones o privatizaciones, han dibujado un nuevo panorama en el que debemos explicar los viejos conceptos. No es que haya muerto el servicio público o que haya nacido una nueva noción que lo sustituya. No, lo que ha pasado y está pasando es que la realidad de las cosas hace emerger nuevas caracterizaciones de conceptos centrales. En este caso, por ejemplo del servicio público y del nuevo Derecho Europeo en la materia, cuestión que estudiaremos a continuación.

La Comisión Europea, como sabemos, distingue, en el inicio de su Libro Verde, entre cinco conceptos:
a) Servicio de interés general
b) Servicio de interés económico general
c) Servicio público
d) Obligación de servicio público
e) Empresa Pública

Sin embargo, a lo largo del Libro Verde se refiere a otro concepto de gran trascendencia, cual es el concepto de servicio universal y sorprende que no haya sido incluido junto a las otras definiciones. La omisión de una definición inicial del concepto de servicio universal pone de manifiesto las extraordinarias dificultades para distinguir tal concepto de los otros cinco definidos, de la misma manera que es difícil distinguir con precisión entre el servicio de interés (económico) general, la obligación de servicio público y el servicio público, debido a las divergencias terminológicas, a la confusión semántica y a las diversas tradiciones existentes en los Estados miembros. El servicio universal es un principio del ordenamiento jurídico comunitario que garantiza el acceso a un servicio de calidad especificada, a un precio asequible, a todos los ciudadanos, independientemente de su situación económica, social o geográfica.

Según el Derecho Comunitario, todos los servicios que las autoridades nacionales consideren de interés general, tienen obligaciones de servicio público, sean o no de contenido económico. En el Derecho Español, tras haber sido configuradas las telecomunicaciones en 1987 como servicios esenciales de titularidad estatal reservadas al sector público, hoy, la ley de 2003, reconoce su condición de servicios de interés general. Ello es muy importante porque desaparece la titularidad estatal aunque no su presencia, ya que es necesario también velar por la mejor satisfacción del interés general. De ahí que hoy éste sector sea un sector regulado. Regulación que aconseja que se eviten las posiciones de dominio, por una parte, $y$, por otra, que determinadas prestaciones, lleguen al conjunto de la ciudadanía en condiciones de igualdad y calidad. Pues bien, esta dimensión positiva del quehacer administrativo que garantiza la accesibilidad, la igualdad y la calidad supone la existencia de las Ilamadas obligaciones de servicio público, entre las que se encuentra el servicio universal. El sentido de estas obligaciones es bien sencillo: garantizar un mercado libre de posiciones dominantes entre los empresarios y de usuarios mal atendidos.

Las telecomunicaciones son, por tanto, un servicio económico de interés general, con unas obligaciones de servicio público, siendo el servicio universal, me parece la más destacada.

En el Derecho Comunitario, desafortunadamente, no se distingue con claridad suficiente el concepto de servicio económico de interés general y servicio público. Quizás, como ocurre en la polémica doctrinal referida al concepto de servicio universal, porque para muchos sigue pesando lo suyo la clásica noción de servicio público y, por ello, no resisten la desaparición del concepto y se felicitan porque el "nuevo servicio público" sea el servicio universal.

De acuerdo con el artículo 22.1 de la nueva Ley de 2003, el servicio universal se define como "el conjunto definido de servicios cuya prestación se garantiza para todos los usuarios finales con independencia de su localización geográfica, con una calidad determinada y a un precio asequible". Calidad, accesibilidad y asequibilidad podrían ser las tres notas que hoy caracterizan el concepto de servicio universal en materia de telecomunicaciones y que supondrían obligaciones de servicio público en la medida en que la Administración debe garantizar su efectividad.

La obligación de servicio universal es una obligación de servicio público. Sí, pero, insisto, en un contexto en el que el servicio público se utiliza en sentido amplio. Por otra parte, el concepto de servicio universal surge en los modelos liberalizados de las telecomunicaciones europeas y en el marco de los denominados servicios básicos de telecomunicaciones (en cuanto contrapuestos a los servicios de valor añadido $)^{3}$ que pasan de ser servicios públicos "stricto sensu" o servicios económicos de interés general sin que por ello, se niegue, sólo faltaría, el acceso de cualquier ciudadano a determinadas prestaciones básicas. La clave, pues, reside en determinar en concreto cuales sean esas prestaciones básicas. Con carácter general, se puede afirmar que la cuestión se centra en garantizar, al menos, el servicio telefónico entonces llamado básico, que hoy podríamos identificar como el servicio telefónico fijo.

En realidad, el servicio universal sólo se aplica en entornos liberalizados, por lo que malamente puede contemplarse como la encarnación del viejo concepto de servicio público. Insisto, otra cosa, bien distinta, es que, en efecto, se admita que la representación del 
nuevo concepto de servicio público camine por nuevos senderos y renuncie a dogmas y criterios rígidos que hoy por hoy no se compaginan bien con un ambiente que riñe, y no poco, con la noción de monopolio, por cierto asociado en origen al concepto de servicio público, hasta constituir una nota esencial e inevitable de la figura jurídica. Sin embargo, el servicio público sigue siendo lo que fue. Lo que ha ocurrido es que la realidad nos ha llevado a nuevos conceptos, hoy de gran utilización, como es, el de servicios de interés económico general.

Ciertamente, el servicio universal implica una presencia de la Administración pública que, si bien no puede ser la propia y privativa del régimen de servicio público, implica, en cierta medida, una determinada intervención pública. Como ha señalado RAPP, "no se trata del concepto de servicio público en el sentido tradicional del término. Es una especie de sintesis entre el objetivo de un mercado más comercial y la preocupación de una cierta continuidad del servicio, una especie de intento de conciliación de los principios del servicio público con los de la economía de mercado" ${ }^{\prime 4}$. Formulación que me parece exacta, atinada y actual. Exacta porque plantea en sus justos términos la funcionalidad del servicio universal en el contexto de los principios del sistema de servicio público y de la economía de mercado. Atinada porque acierta a contextualizar la cuestión y, actual, porque es un problema, indudablemente, de nuestro tiempo.

El concepto de servicio universal, me parece, es la expresión en el mundo del Derecho Administrativo de los postulados del pensamiento abierto, dinámico y complementario. Además, demuestra a las claras que el relativismo y la instrumentalidad son notas que acompañan al propio Derecho Administrativo en su largo peregrinar. ¿Por qué? Porque se complementan elementos del régimen de servicio público (continuidad, regularidad) y del mundo del mercado (no monopolio) en su ejercicio de integración que, de verdad, refleja la actualidad de las técnicas del Derecho Administrativo aplicadas a la realidad del momento, sin necesidad de acudir a una añoranza del pasado queriendo ver lo que ya no existe, porque no puede existir.

La ley de 2003, que profundiza en la libre competencia desector, introduce, como parece lógico una vez transmitido cierto tiempo desde la liberalización, mecanismos correctores que garanticen la aparición y viabilidad de operadores distintos a los titulares del antiguo monopolio. Es, me parece, una medida de sentido común y de sentido jurídico relevante para evitar que la libre competencia pueda ser ficticia o aparente. Además, y esto es lo que me interesa destacar ahora, se refuerza la protección jurídica de los usuarios, ampliándose el elenco que elementos de la obligación del servicio universal.

En efecto, como se reconoce en la propia exposición de motivos, la ley de 2003 recoge la ampliación de las prestaciones que, como mínimo esencial, deben garantizarse a todos los ciudadanos, bajo la denominación de servicio universal. En concreto, en el artículo 22, se incluyen, a las que ya establecía el legislador de 1998, el acceso funcional a internet $y$ la posibilidad de que se ofrezcan opciones tarifarias especiales que permiten un mayor control del gasto por los usuarios.

El contenido mínimo del servicio universal lo fija el Reglamento y se resume en los siguientes extremos. Todos los ciudadanos pueden recibir conexión a la red pública telefónica fijo y acceder a la prestación del servicio telefónico fijo disponible para el público. Todos los abonados al servicio telefónico deben disponer gratuitamente de una guía telefónica, actualizada e impresa y unificada para cada ámbito territorial, que, como mínimo, será de ámbito provincial. Que exista una oferta suficiente de teléfonos de pago en el dominio público, en todo el territorio nacional. Que los usuarios discapacitados o con necesidades sociales especiales, tengan acceso al servicio telefónico fijo disponible al público en condiciones equiparables a las que se ofrecen al resto de los usuarios. Ahora, de acuerdo con la nueva ley, se añaden, como comenté anteriormente, dos nuevas obligaciones para los operadores que artículo 23 - designe el Ministerio para atender el servicio universal.

Hoy, guste más o menos, los monopolios se terminan, la reserva en exclusiva se cae sola, lo cual no quiere decir, ni mucho menos, que el mercado se deba contemplar desde la unilateralidad. No, el mercado ni es ni puede ser la fuente del Derecho, es el contexto en el que debemos trabajar y en el que debemos interpretar el Derecho Público para que en ningún momento claudique ante el sentido y la misión que tiene: garantizar el bienestar de todos.

Hoy, la Administración debe cumplir cabalmente su función garantizadora para que se respeten las reglas de juego. Ello supone reconocer el papel central en materia de servicios regulados del usuario a quien hay que facilitar la accesibilidad, la calidad y la asequibilidad, justo las tres caracteristicas que definen el servicio universal.

Ciertamente, sin la historia del servicio público, hoy no podríamos encontrar soluciones en los contextos regulados. Regularidad, continuidad... son notas del servicio público que son válidas también para servicios de interés general, como se denominan hoy los servicios públicos liberalizados.

Por tanto, la tarea de la Administración pública es muy importante para preservar el servicio universal. $\mathrm{Ni}$ puede abusar de su posición para someter al empresario a situaciones irracionales, ni debe tolerar que el mercado castigue a los más débiles. Por eso, hoy más que nunca, el Derecho Administrativo se presenta como el Derecho del Poder para la libertad 